\title{
El cooperativismo en el área del café
}

\section{Cooperativism in the coffee area}

\section{Cruz Mercado, Tatiana Josefa; Castillo Centeno, Urania Suhey; Gadea- Toledo, Ana Karina; Toruño, Editor Académico Prof. Dr. Pedro José}

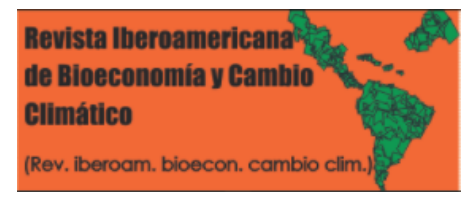

\author{
Tatiana Josefa Cruz Mercado \\ tatianacruz@yahoo.com \\ Universidad Nacional Autónoma de Nicaragua, León. \\ CUR Jinotega., Nicaragua \\ Urania Suhey Castillo Centeno \\ tatianacruz@yahoo.com \\ Universidad Nacional Autónoma de Nicaragua, León. \\ CUR Jinotega., Nicaragua \\ Ana Karina Gadea- Toledo \\ tatianacruz@yahoo.com \\ Universidad Nacional Autónoma de Nicaragua, León. \\ CUR Jinotega., Nicaragua \\ Editor Académico Prof. Dr. Pedro José Toruño \\ Universidad Nacional Autónoma de Nicaragua, León. \\ Escuela de Ciencias Agrarias y Veterinarias., Nicaragua
}

Revista Iberoamericana de Bioeconomía y Cambio

Climático

Universidad Nacional Autónoma de Nicaragua, León, Nicaragua ISSN-e: 2410-7980

Periodicidad: Semestral

vol. 4, núm. 8, 2018

czuniga@ev.unanleon.edu.ni

Recepción: 18 Febrero 2018

Aprobación: 14 Noviembre 2018

URL: http://portal.amelica.org/ameli

jatsRepo/394/3941755004/index.htm

DOI: https://doi.org/10.5377/ribcc.v4i8.6715

Autor de correspondencia: tatianacruz@yahoo.com
Resumen: El presente estudio se centró en analizar el cooperativismo en la producción y comercialización del café en Nicaragua. El rubro café representa el 50\% del valor total de la exportación de productos agrícolas en la región Centroamericana. En los años 2010 y 2011, el café ha representado el $60 \%$ y el $69 \%$ respectivamente del valor total de los productos agropecuarios exportados por Nicaragua, siendo el café la cuarta fuente de divisas del país, luego de las remesas familiares, la inversión extranjera directa y la cooperación externa.

Palabras clave: Exportaciones, Cooperativas, COOMAPCOJ R L, Microcrédito, Café.

Abstract: The present study focused on analyzing the importance of coffee production and marketing in Nicaragua. The coffee item represents $50 \%$ of the total value of the export of agricultural products in the Central American region. In 2010 and 2011, coffee represented $60 \%$ and $69 \%$ respectively of the total value of agricultural products exported by Nicaragua, with coffee being the fourth largest source of foreign currency in the country, after family remittances, foreign investment direct and external cooperation.

Keywords: Exports, Cooperatives, COOMAPCOJ R L, Microcredit, Coffee.

\section{INTRODUCCIÓN}

El rubro café representa el 50\% del valor total de la exportación de productos agrícolas en la región Centroamericana. En los años 2010 y 2011 , el café ha representado el $60 \%$ y el $69 \%$ respectivamente del valor

\section{NotAS DE AUTOR}


total de los productos agropecuarios exportados por Nicaragua, siendo el café la cuarta fuente de divisas del país, luego de las remesas familiares, la inversión extranjera directa y la cooperación externa (Montoya, 2012).

Actualmente los mercados de café diferenciados, están demandando la relación con el origen, trazabilidad e inocuidad en los productos que importan, por lo que los países exportadores como Nicaragua deben contar con una estructura y procesos de beneficiado que mantengan la calidad del café, para poder exportar y cumplir con los parámetros de calidad del mercado internacional. Así como los estudios que demuestren su relación con el origen. Teniendo en cuenta las exigencias para la exportación del café y siendo el departamento de Jinotega una de las zonas productoras de café de la zona Norte de Nicaragua (Montoya, 2012).

Las cooperativas cafetaleras de Jinotega, como se da el comercio nacional de café, y la importancia de este para la economía del país, ya que este sector aporta entre el 4 y 7 por ciento del PIB a la economía nacional, generando 300,000 empleos directos e indirectos, cabe destacar que el café es el principal rubro de exportación de Nicaragua (Lanuza, 2016).

Por otra parte, la apertura comercial de Nicaragua hacia nuevos mercados a través de la firmas de tratados libre comercio y la apertura a un modelo de mayor competitividad como es la globalización de mercados de mayor competitividad, ofrece nuevas oportunidades y retos que obligan estas organizaciones a elevar su nivel de competitividad y realizar transformación en la operación y visión, esto con el fin de lograr aprovechar espacios comerciales ofreciendo productos y servicios de calidad, Como clave para el éxito de estas empresas.

\section{Antecedentes del cooperativismo agropecuario}

En América Latina, encontramos los orígenes del cooperativismo analizando el marco de las contradicciones existentes en la estructura latifundio-minifundio, en la lucha del campesinado por acceder a la tierra bajo diversas formas de propiedad y organización de los servicios y frente a la actitud señorial de las burguesías políticas de turno. Es difícil pensar en alguna actividad económica, que no se lleve a cabo en alguna parte del mundo por medio de cooperativas. Estas actúan en la producción y distribución de bienes, en la agricultura, el mercadeo, el crédito, el transporte, las manufacturas, la banca, los seguros, la vivienda, las industrias pesqueras y forestales, en servicios de diversas clases y en muchos otros campos El movimiento cooperativo mundial se caracteriza por su gran variabilidad. En relación al tamaño de la cooperativa, estas van desde la cooperativa pequeña a la grande y a la muy grande. Existen muchos miles de pequeñas cooperativas con menos de 100 socios, o aún menos de 10, pero hay muchas de tamaño mediano y algunas de proporciones enormes. No existe tamaño ideal para las cooperativas, aunque generalmente se reconoce que se administran con mayor facilidad las unidades más pequeñas (Matus J, 2015).

La Cooperativa Multisectorial Agrupación de Productores Orgánicos de Jinotega (COOMAPCOJ R.L, 2011), es una organización cooperativa de primer grado, fundada el 14 de marzo del 2003, según resolución Acta Constitutiva del día 21 de noviembre del año 2003, nace con la asociación de 21 productores de las comunidades de Pavona Central, Monterrey, Loma Alta ubicadas en el departamento de Jinotega (COOMAPCOJ R.L, 2011).

Los servicios y actividades que desarrolla COOMAPCOJ R.L El Microcrédito:

Se está iniciando con el financiamiento de 60 asociados, se financiarán 120 manzanas de café, se financiaran 400 dólares por manzanas, el financiamiento estará convenido con la comercialización de un contenedor de café, esta negociación se desarrolla con un comercializador Local "Family Coffee" J\&M; también se trabaja una propuesta de financiamiento con BIOSFAIR. SA, para una la habilitación de un contenedor de café (COOMAPCOJ R.L, 2011).

\section{Asistencia Técnica:}

Dirigido al seguimiento técnico, la capacitación como medida de brindar conocimiento y aplicación de técnicas donde permita la tecnificación de los cultivos, para mantener el buen manejo de las plantaciones de café, con un monitoreo constante en el desarrollo de las enfermedades y la nutrición del cultivo; también se buscará fortalecer la asistencia técnica con el fin monitorear la buena ejecución de los programas de crédito, así como la recuperación en tiempo y forma (COOMAPCOJ R.L, 2011). 


\section{La Comercialización:}

Después de una mala experiencia en la comercialización, en la cosecha 2011-2012, por efecto del mercado la Cooperativa pedio en ese ciclo US\$ 47,000.00 Dólares, por efecto de la variabilidad de precio y compra de inventarios de café, que a la hora de acopio el precio estaba por encima del precio de venta final, conllevo a una situación muy difícil para la Cooperativa, lo cual fue un aprendizaje y en la actualidad se ha estado trabajando con intención de compra de futuro, con modalidad de fijación de futuro, ha resultado muy positivo y nos evitamos serios problemas de liquides y endeudamiento, en los últimos dos años la cooperativa esta solvente con sus compromisos, y se fortalece con relaciones comerciales muy estables en la comercialización, el acopio, y la adquisición del microcrédito, y servicios de abastecimientos para nuestros asociados (COOMAPCOJ R.L, 2011).

Al 2004-2007, realiza alianza estratégica con ALDEA GLOBAL, AVODEC, OXFAM, COOPERACION ESPAÑOLA, fortalece la organización productiva, consigue apoyo en servicios de asistencia técnica, financiamiento, comercialización (COOMAPCOJ R.L, 2011).

Entre 2008-2014, recibe apoyos de organizaciones para la Comercialización 16 contenedores de café comercializados con: COOMCAFE, CECOSPROCAES, ALDEA GLOBAL, BIOSFAIR, J\&M, Recibe apoyo financiero de INTERMON OXFAM, Fundación para el desarrollo Tecnológico Agropecuario y Forestal (FUNICA), CATIE. De estas últimas organizaciones se recibe el apoyo para mejorar el proceso de fortalecimiento organizativo de los productores, y la asistencia técnica (COOMAPCOJ R.L, 2011).

Actualmente, con los proyectos AVODEC, BIOSFAIR, AXIOM COFEE VENTURES Y TECHNO SERVE, COOM-APCOJ R.L logra definir su política de crédito, Plan estratégico y manuales/ procedimientos administrativos. Y asistencia Técnica entre las perspectivas de futuro se tienen: incrementar la comercialización de un contenedor de café orgánico certificado con el comprador Austríaco "Puertas del Sol"; se firma contrato de financiamiento con un comercializador. (Krotz. E, 1992)

local J\&M, el fondo es para el financiamiento de 60 productores/as; se reactivara una planta de procesamiento de abono orgánico; se buscara el fortalecimiento de estructura y logística de acopio en 5 comunidades que recolectaran el acopio del café de los asociados; iniciar relación comercial con AXIOM COFFEE VENTURES, la propuesta para el presente ciclo es realizar la venta de dos contenedores de café (COOMAPCOJ R.L, 2011).

La oficina de la Cooperativa está ubicada en la cabecera departamental de Jinotega, los socios están ubicados en los municipios de:

Municipio del Cuá:

Comunidades de Pavona central, Abisinia.

Municipio de Santa María de Pantasma:

Comunidades de: Loma Alta, Las Cruces, El Plátano, Los Planes.

Municipio de San Rafael del Norte:

Comunidad de: Santa Isabel, Soledad, Loma Azul.

Municipio de Jinotega:

Comunidad de: Asturias, Monterrey, Los Cerrones, Las Cuchillas, Toma Yunca y Mancotal, Antioquia, y La Reforma.

a) La cantidad de socios(as) que da asistencia y servicios la cooperativa es de 120 socios (as).

b) El principal rubro es la producción de Café Arábiga, asistiendo 480 manzanas de café en producción.

c) con una producción total de 11,500.00 quintales pergaminos.

d) Se comercializó 3,500.00 quintales pergaminos; comercializados a compradores nacionales y un comprador Austriaco de la BIOSFAIR SA, quien exporta a Austria.

e) El personal administrativo está compuesto por el Coordinador Técnico, Responsable de Cartera y Cobro y Asistente Administrativo. 
f) Los servicios de asistencia técnica, y el financiamiento, los socios reciben el apoyo con la organización no gubernamentales Technoserve a través de proyecto cosechemos más Café, enfocando en la asistencia técnica, fortalecimiento organizativo, empresarial y comercial de la cooperativa y sus socios (as).

\section{Literatura Citada}

COOMAPCOJ R.L. (2011). Plan estrategico COOMAPCOJ R.L. Obtenido de Plan estrategico COOMAPCOJ R.L.

Matus Lazo Javier. (2015). cooperativismo agropecuario en Nicaragua. Obtenido de cooperativismo agropecuario en nicaragua: http://www.agronicaragua.org/Textos_Completos/ CIPRES/2\%20el\%20cooperativis moagropecuarioNic.comped.pdf

Krotz, E. (1992). cooperativismo rural en México. Revistas UNAM, vol.23. N.88. Obtenido de cooperativismo rural en México: http://www.revistas.unam.mx/index.php/pde/article/viewFile/34498/31435

Lanuza, M. d. (2016). Factores que han influido en el bajo rendimiento de la producción de café de las cooperativas de Jinotega Nicaragua. Obtenido de Factores, http://repositorio.unan.edu.ni/id/eprint/2013

Montoya, A. A. (2012). El café como pilar económico. Obtenido de El café como pilar económico: https:// alvaroaltamirano.wordpress.com/2012/01/ 